\title{
Comparison of isobaric levobupivacaine versus hyperbaric bupivacaine in spinal anesthesia for cesarean section: A prospective randomized case control study
}

\author{
Madhanmohan C ${ }^{1}$, Udita Naithani ${ }^{2, *}$, Megha Gupta ${ }^{3}$, Virendra Verma ${ }^{4}$, Pankaj Damor ${ }^{5}$ \\ ${ }^{1}$ Senior Resident, ${ }^{2}$ Professor, ${ }^{3,5} \mathrm{PG}$ Student, ${ }^{4} \mathrm{Ex}$. PG Student, Dept. of Anesthesiology, RNT medical college, Udaipur, \\ Rajasthan, India
}

*Corresponding Author: Udita Naithani

Email: uditanaithani@gmail.com

Received: $15^{\text {th }}$ July, 2018

Accepted: $15^{\text {th }}$ October, 2018

\begin{abstract}
Introduction: Isobaric levobupivacaine is now being investigated in spinal anesthesia owing to its better safety profile; however, the studies are sparse which show clinical efficacy of intrathecal isobaric levobupivacaine alone in its ED95 dose (12.5-13.5mg) for cesarean sections (CS) and its comparison with most commonly used regime of hyperbaric bupivacaine (10mg).

Objective and Methods: 100 parturients undergoing CS in spinal anesthesia were randomized in two equal groups to receive either $12.5 \mathrm{mg}$ isobaric levobupivacaine (group L) or 10mg hyperbaric bupivacaine (group B). Sensory - motor block characteristics (onset, extent, and duration), hemodynamic profile, adverse effects and success rate of the two drugs were compared.

Results: All patients in both groups achieved target sensory level of $\mathrm{T}_{6}$ and Bromage score of 3 (complete motor block) hence no patient required anesthetic supplementation resulting in $100 \%$ success rate in both groups. Sensory onset (Time to $\mathrm{T}_{6}$ ) was significantly faster in group B $(3.8 \pm 0.81 \mathrm{~min})$ than in Group L $(4.28 \pm 1.04 \mathrm{~min}) \mathrm{p}=0.011$. Motor onset (Time to B3) was also significantly faster in Group B (3.04 \pm 0.69$)$ than in group L $(3.56 \pm 0.63), p=0.0002$. However this difference of $<1$ min was clinically insignificant. Duration of analgesia, sensory blockade and motor blockade were significantly longer in group B than group L, $\mathrm{p}=0.0001$. Hemodynamically both groups were comparable.

Conclusion: Isobaric levobupivacaine $(12.5 \mathrm{mg}$ ) can be used as an alternative to hyperbaric bupivacaine (10mg) in spinal anesthesia for cesarean section as it offers effective sensory motor blockade with clinically comparable onset time.
\end{abstract}

Keywords: Isobaric levobupivacaine, Hyperbaric bupivacaine, Spinal anesthesia, Caesarean section.

\section{Introduction}

Spinal anesthesia is one of the preferred means for caesarean section (CS), as it is easy to administer thereby producing quick onset of anaesthesia. It carries high efficiency; no airway related problems, minimal neonatal depression, better control of cardiovascular and stress responses. ${ }^{1}$ As far as cesarean section is concerned spinal anaesthesia using racemic bupivacaine is the widely practiced technique in the present era. Levobupivacaine which is a $\mathrm{S}(-)$ enantiomer of bupivacaine got properties of lower cardioneurotoxicity with comparatively shorter motor block duration; hence its use is widely being increased though there is scarcity of data showing its use in obstetric anesthesia.

While performing spinal anesthesia hyperbaric solutions of local anesthetics are preferred as their spread is favoured by gravity, so that they can ascend faster thereby achieving higher sensory level with faster onset. $^{2}$ However, hyperbaric levobupivacaine are not introduced into the market till now and making it hyperbaric in every case is not advisable as the concentration may be affected.

Recently data are appearing in literatures which have shown that isobaric levobupivacaine is effective in spinal anesthesia to accomplish various surgeries, including caesarean section..$^{3,4}$ Previously conducted studies observed that isobaric levobupivacaine remains truly isobaric with respect to CSF of pregnant woman thus causing a uniformly predictable blockade. ${ }^{5}$ However plain bupivacaine remains clinically hypobaric which produces unpredictable sensory blockade like either high spread which was not desired or a low grade blockade which is not sufficient enough for the surgery. ${ }^{6}$ For this reason hyperbaric bupivacaine is favoured in obstetric anesthesia. Hyperbaric bupivacaine $(2 \mathrm{ml}=10 \mathrm{mg})$ is standard drug regime in spinal anesthesia for CS as used in many studies. ${ }^{7}$

Clinical effectiveness of plain levobupivacaine in doses approximating $\mathrm{ED}_{95}$ dose are not much studied. Hence present study was decided to evaluate clinical efficacy of $12.5 \mathrm{mg}$ isobaric levobupivacaine which approximates the $\mathrm{ED}_{95}$ dosage for $\mathrm{CS}$ in spinal anesthesia and compared it with conventionally used regime of $10 \mathrm{mg}(0.5 \%, 2 \mathrm{ml})$ hyperbaric bupivacaine regarding sensory - motor block characteristics, success rate, hemodynamic profile, complications etc. Hypothesizing that this much dose of levobupivacaine will compensate for the potency difference with bupivacaine and produce equivalent block characteristics. Ultimate objective of present study was to find if isobaric levobupivacaine produces effective anesthesia to accomplish surgery, it could become a better alternative to hyperbaric bupivacaine as it is safe comparatively in terms of toxicity. 


\section{Material and Methods}

After taking approval from ethical committee the present study was carried out in Department of Anesthesia in a tertiary care hospital. Informed written consent for taking part in the study was taken from 100 parturients (18-30yr, $40-80 \mathrm{~kg}, 150-170 \mathrm{~cm}$, ASA II), who were scheduled for elective CS under spinal anesthesia for indications like previous CS, primi breech, postdatism, cord around neck, cephalopelvic disproportion, non-progress of labor, etc. Thorough preanesthetic evaluation including history, physical examination and necessary investigations was done, for selection of patients. Exclusion criteria were patient refusal, contraindication to spinal anesthesia, morbid obesity, allergy to amide local anesthetics, fused spine, musculo skeletal abnormalities, coagulation defects etc.

Study Design: A prospective, randomized, double blinded, comparative case-control study. Consort flowchart is shown in Chart 1.

\section{Chart 1: Consort flow chart}

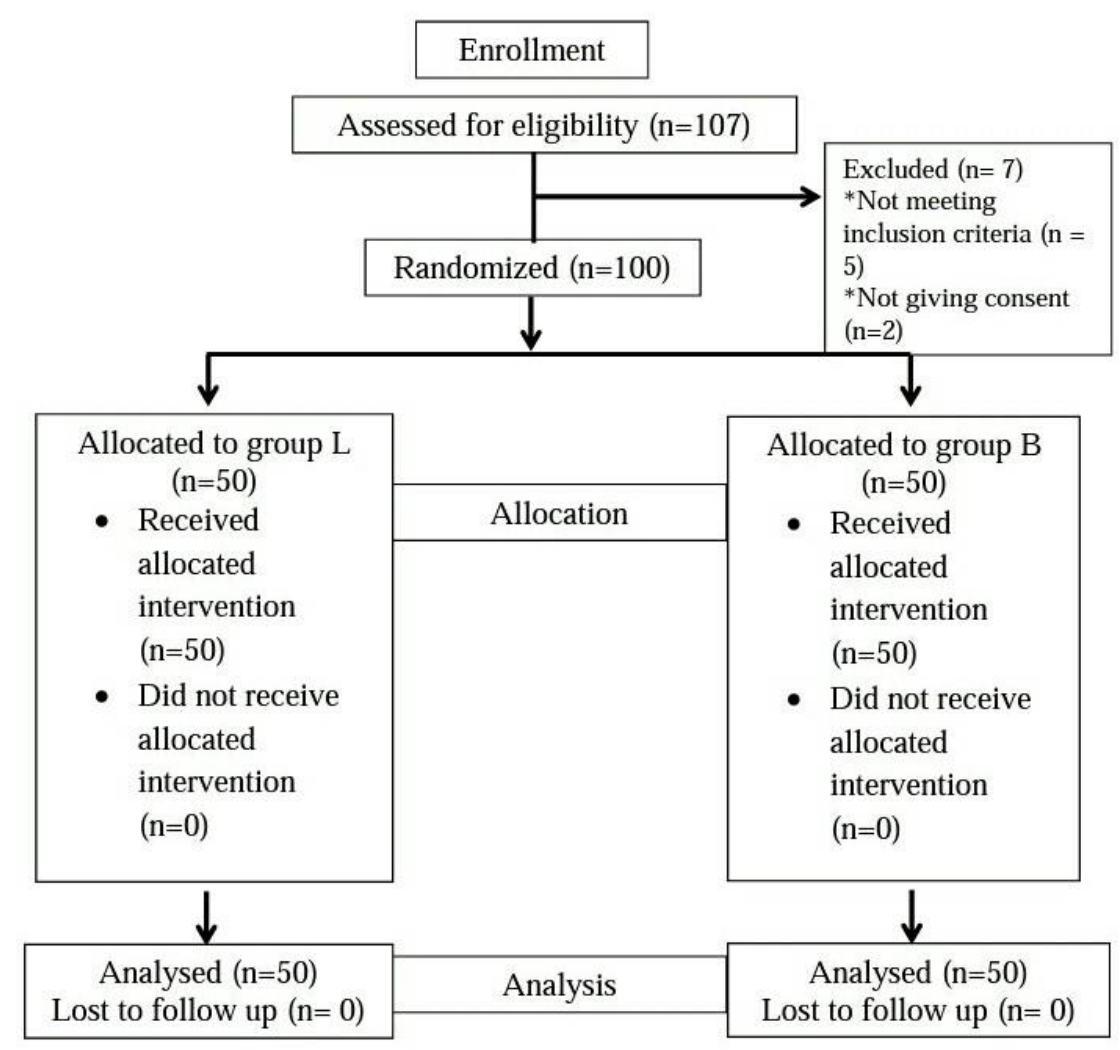

Basis of Sample Size: Based on a previous study by Duggal $\mathrm{R} \mathrm{et} \mathrm{al}^{7}$ to detect a difference of $3 \mathrm{~min}$ for the time to maximum motor block, a sample size of 48 in each group was required with $95 \%$ confidence interval and power of $80 \%$. Hence we enrolled 100 patients in the study consisting of 50 in each group to compensate for dropouts. Null hypothesis for the study was that isobaric levobupivacaine $(12.5 \mathrm{mg})$ is not inferior to hyperbaric bupivacaine $(10 \mathrm{mg})$ in spinal anesthesia for caesarean section. Patients were randomized into two groups of 50 each using sealed envelope technique as Group L (Levobupivacaine) and Group B (Bupivacaine).

The primary outcome of the study was success rate in terms of percentage of cases in whom surgery could be completed without supplementation. Secondary outcomes were sensory and motor onset time, peak sensory level, maximum Bromage score, duration of sensory -motor block, duration of analgesia, need for supplementation analgesia, changes in blood pressure and heart rate, incidence of hypotension, bradycardia and other complications if any.

Spinal Anesthesia Technique: Standard fasting guidelines followed, peripheral intravenous line using $20 \mathrm{G}$ i.v. cannula was secured in pre-induction room and Ringer lactate $500 \mathrm{ml}$ was given as preload. In obstetrical operating room multiparamonitor was attached having Non-Invasive Blood Pressure, Electrocardiography and peripheral oxygen saturation $\left(\mathrm{SpO}_{2}\right)$ and baseline vitals were recorded. The patient was placed in left lateral position. Taking full aseptic precautions, lumbar puncture was done in $\mathrm{L}_{3}-\mathrm{L}_{4}$ space via midline approach using $25 \mathrm{G}$ spinal needle (quincke type) [Pricon, Isconsurgicals LTD, Jodhpur], keeping bevel up. After getting free flow of CSF, $0.5 \% 2.5 \mathrm{ml}$ 
(12.5mg)isobaric levobupivacaine (Levo-anawin 0.5\% $4 \mathrm{ml}$ injection, Neon Laboratories Limited, India)] was injected intrathecally. In group B $0.5 \% 2 \mathrm{ml}(10 \mathrm{mg})$ hyperbaric bupivacaine (Bupivacaine Hydrochloride in Dextrose Injection USP, Samarth Life Science, Pvt. Ltd, India) was injected intrathecally. Anesthesiologist who had performed spinal anesthesia did not take part in the further data collection and analysis. Drug volume was different in two groups and not made equal by adding saline as it would have altered the baricity of the solution and can affect the block characteristics. All data were recorded in a proforma by an independent anesthesiologist who was not aware of group allocation. The study was considered double blinded because both researcher (data recorder and analyzer) and patient were unaware of the study drug regime.

Time of end of spinal injection was taken as time zero $\left(\mathrm{t}_{0}\right)$ for further data recording. Hemodynamic variables (Systolic Blood Pressure, Diastolic Blood Pressure, Heart Rate, and $\mathrm{SpO} 2$ ) were recorded at every 5 min interval till 15 min after intrathecal injection then every 15 min till end of the surgery.

Sensory block was assessed in mid clavicular line bilaterally using $24 \mathrm{G}$ hypodermic needle pin prick, and loss of sensation to pinprick was taken as sensory block. Motor block was recorded using modified Bromage score $(0=$ movements full range in hip, knee and ankle; $1=$ no movement in hip but able to move knees and ankle; $2=$ no movement in hip and knee but able to move ankle; $3=$ No movement at hip, knee and ankle joint). Sensory - motor block were assessed every min starting from 2 min after intrathecal injection till the sensory block of $\mathrm{T}_{6}$ along with a Bromage score 3 were achieved, and also at $10 \mathrm{~min}$ to assess the peak sensory level (PSL) and Maximum Bromage score (MBS).

When sensory level of $\mathrm{T}_{6}$ achieved along with Bromage score 2 or 3 , surgery was allowed to start in spinal anesthesia, as mentioned above and the time was noted. If patient complained of intraoperative pain, supplementation to be given was ketamine $(1-2 \mathrm{mg} / \mathrm{kg})$ and / or Propofol (1-2 mg/kg) case was defined as partial success. If pain persisted the case had to be converted to GA and declared as failed case. If there was pain at incision site at $10 \mathrm{~min}$, sensory level below $\mathrm{T}_{10}$ or Bromage score is $<2$ then case was declared as failed case at the start and converted to general anesthesia and excluded from the study.

Data Recording: Data were recorded in proforma by anesthesiologist who was not aware of group allocation as follows:

1. Age, weight, height, indication and duration of surgery

2. Time taken to achieve T6 (sensory onset), time taken to achieve Maximum Bromage score $\mathrm{B}_{3}$ (motor onset), Peak sensory level and Maximum Bromage score

3. Sensory block duration (Time taken to return to S1), Motor block duration (Time taken to return to Bromage score $\mathrm{B}_{0}$ ) and duration of analgesia (Time to first rescue analgesia)

4. Incidence of hypotension (systolic blood pressure $<90 \mathrm{mmHg}$ ), Bradycardia (heart Rate < $60 \mathrm{bpm}$ ). They were treated with mephentermine $6 \mathrm{mg}$ and atropine $0.4 \mathrm{mg}$ respectively.

5. Degree of Success (clinical efficacy) of spinal anesthesia was graded as- Completely successful (no supplemental analgesia is required),Partially successful (single dose of ketamine given) and Failure (conversion to GA)

Clinical efficacy (success rate) was calculated in terms of percentage of cases in whom surgery was completed without need of any intraoperative anesthetic supplementation (completely successful cases), it was presented in percentage as well as descriptive term as per Hopkins scale. ${ }^{8}$

\begin{tabular}{|c|c|c|c|c|c|c|c|}
\hline $\begin{array}{c}\text { Clinical } \\
\text { Efficacy }\end{array}$ & Trivial & $\begin{array}{c}\text { Small } \\
\text { /low }\end{array}$ & Moderate & $\begin{array}{c}\text { Large } \\
\text { /high }\end{array}$ & $\begin{array}{c}\text { Very large /very } \\
\text { high }\end{array}$ & $\begin{array}{c}\text { Near } \\
\text { Perfect }\end{array}$ & Perfect \\
\hline Percentage & $0 \%$ & $10 \%$ & $30 \%$ & $50 \%$ & $70 \%$ & $90 \%$ & $100 \%$ \\
\hline
\end{tabular}

\section{Statistical Analysis}

MS EXCEL sheets were used to enter data collected and analysis done using Statistical Package for Social Sciences (SPSS) version 17 [International Business Management (IBM), Corporations, NewYork, USA]. Categorical (qualitative) data were presented as number (percentage) and compared using chi square test. Continuous variables (quantitative) were presented as mean $\pm \mathrm{SD}$ and compared using $\mathrm{t}-$ test. $\mathrm{p}<0.05$ was considered as statistically significant.

\section{Results}

Demographically group B and group L were both comparable in terms of age, ASA status, duration of surgery and vital parameters during preanesthetic evaluation. (Table 1)

Sensory Motor Block Characteristics: Sensory onset (Time to T6) was significantly faster with hyperbaric bupivacaine (3.8 $\pm 0.81 \mathrm{~min}$ in Group B) as compared to isobaric levobupivacaine $(4.28 \pm 1.04 \mathrm{~min}$ in Group L), $\mathrm{p}$ $=0.011$ [Fig. 1]; though this difference of less than 1 min was unlikely to be significant clinically. All patients of both groups achieved target sensory level of $\mathrm{T}_{6}$ which was necessary to start caesarean section in spinal anesthesia. Peak sensory level at 10 min ranged from $\mathrm{T}_{3}-\mathrm{T}_{6}$ in both groups however median value was $\mathrm{T}_{6}$ in group $\mathrm{L}$ as compared to $\mathrm{T}_{4}$ in group $\mathrm{B}$. Mean value of peak sensory level was comparable in two groups $\left(\mathrm{T}_{4.74 \pm 1.03}\right.$ in group $\mathrm{B}$ and $\mathrm{T}_{5.12 \pm 0.97}$ in group $\mathrm{L}, \mathrm{p}$ 
$=0.060)$. The time to reach peak sensory level was also statistically comparable in two groups $(4.68 \pm 0.81 \mathrm{~min}$ in group L, 4.44 \pm 0.63 min in group $\mathrm{B}, \mathrm{p}=0.095$ ) [Fig. $1]$.

Complete motor block with maximum Bromage score of 3 achieved all patients of both groups. Motor onset in terms of time to achieve maximum Bromage of 3 was significantly faster with hyperbaric bupivacaine (3.04 $\pm 0.69 \mathrm{~min}$ in Group B) as compared to isobaric levobupivacaine $(3.56 \pm 0.63 \mathrm{~min})$ in group $\mathrm{L}), \mathrm{p}=0.0002$ [Fig. 1], however this difference of less than 1 min was unlikely to be clinically significant.

Duration of analgesia, sensory block and motor block were significantly longer in Group B as compared to Group L, p=0.0001 [Fig 2].

Hemodynamic Parameters: There was no significant difference in mean value of pulse rate, $\mathrm{SpO}_{2}$, (systolic BP and diastolic BP) [Fig 3] in both groups throughout the study period $(\mathrm{p}>0.05)$.
Adverse Effects: Adverse effects observed in this study were hypotension [36\% $(n=18)$ in Group B and $28 \%$ $(\mathrm{n}=14)$ in group L] and Perioperative nausea and vomiting [8\% $(n=4)$ in group B and $4 \%(n=2)$ in group L]. Their incidence was comparably more in Group B but could not make a statistically significant difference, $\mathrm{p}>0.05$. No neonatal complications occurred requiring intensive care. Also no maternal morbidity or mortality was observed in the study.

Success Rate (clinical efficacy) of Spinal Block: Incidence of "completely successful" spinal block (no supplementation) was $100 \%(n=50)$ in both the groups. None of the patient in both groups required anesthetic supplementation or general anesthesia. As per Hopkins scale, both $12.5 \mathrm{mg}$ isobaric levobupivacaine and $10 \mathrm{mg}$ hyperbaric bupivacaine in spinal anesthesia were graded as "perfect agent" for CS, owing to $100 \%$ complete success rate in both groups.

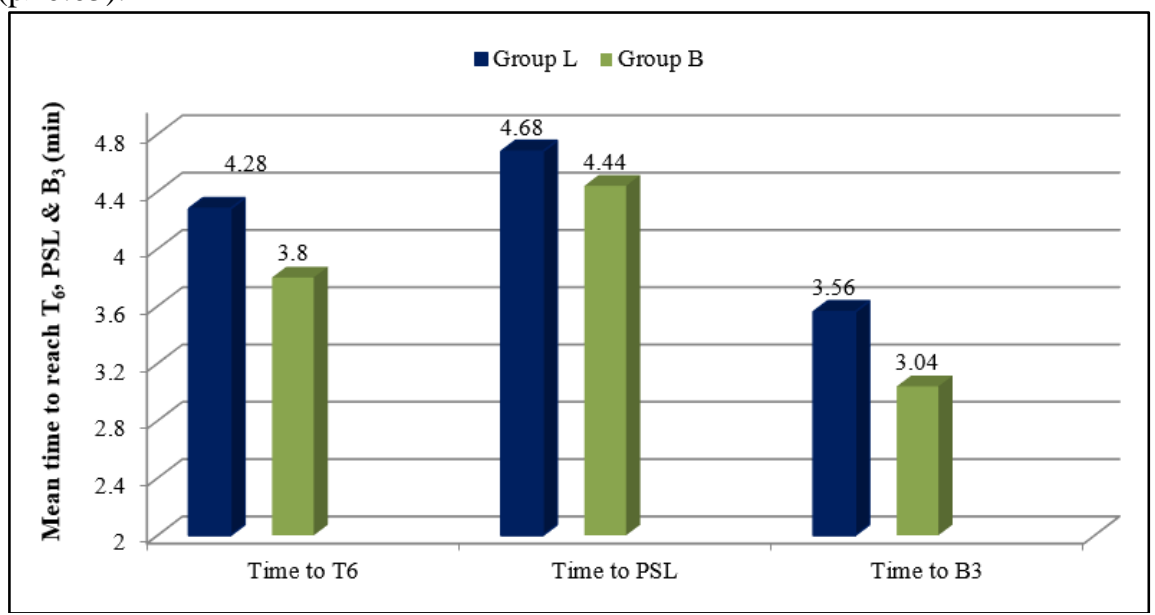

Fig. 1: Mean time to achieve $T_{6}$ sensory blockade, Peak Sensory level and Bromage score 3 (B)

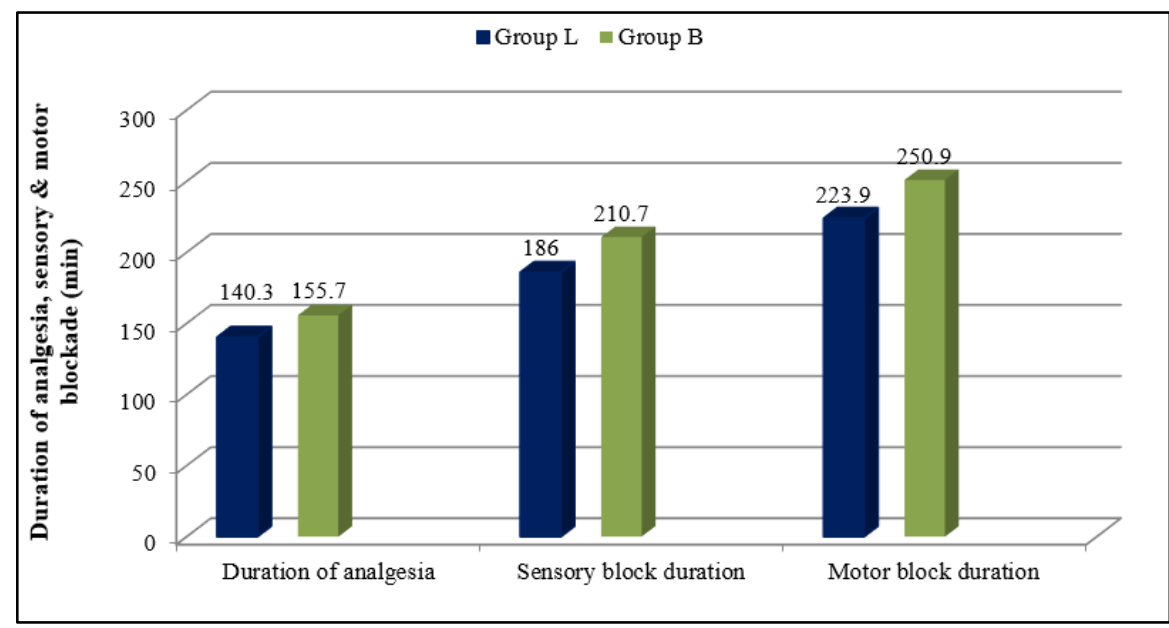

Fig. 2: Mean duration time of analgesia, sensory blockade and motor blockade 


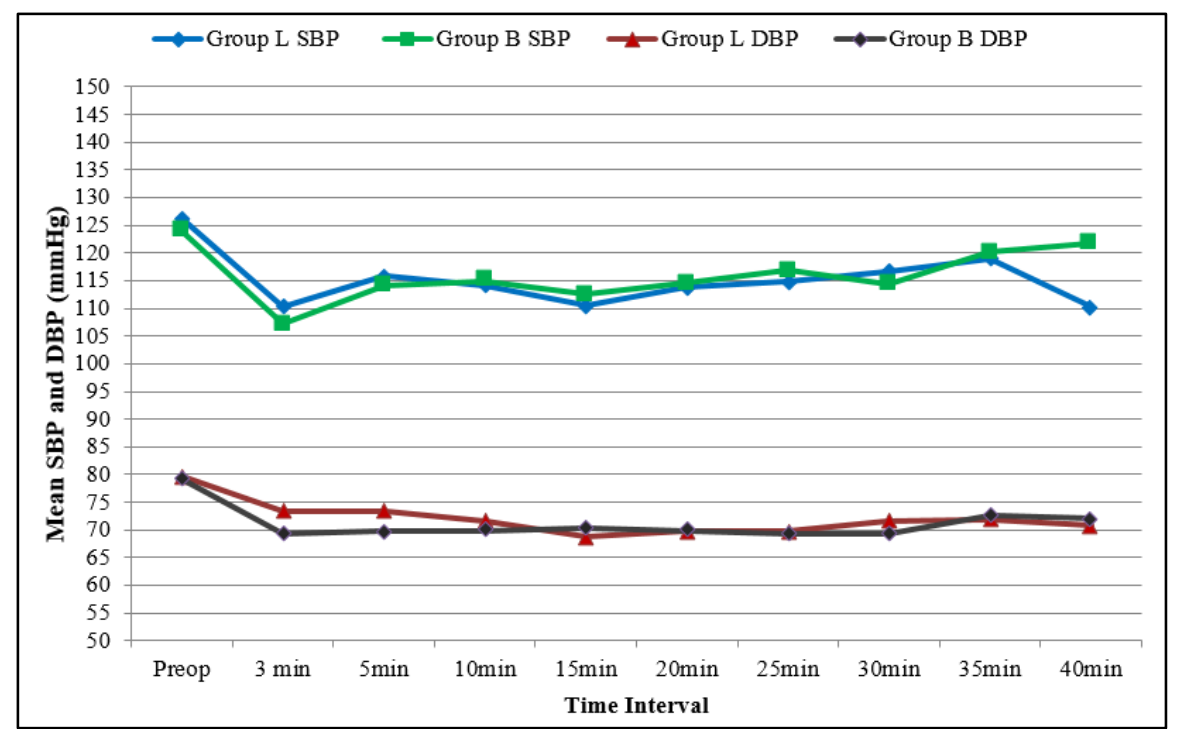

Fig. 3: Comparison of SBP and DBP of both groups

Table 1. Baseline characteristics

\begin{tabular}{|c|c|c|c|}
\hline Variables & $\begin{array}{c}\text { Group L } \\
(\mathbf{n}=50)\end{array}$ & $\begin{array}{c}\text { Group B } \\
(\mathbf{n}=50)\end{array}$ & P value \\
\hline Age (years) & $25.10 \pm 2.38$ & $24.82 \pm 3.11$ & 0.614 \\
\hline Weight (kg) & $61.2 \pm 5.75$ & $61.60 \pm 5.21$ & 0.716 \\
\hline Height $(\mathrm{cm})$ & $159.34 \pm 5.39$ & $159.22 \pm 5.72$ & 0.914 \\
\hline \multicolumn{4}{|c|}{ Indication of Cesarean } \\
\hline Previous Cesarean & $21(42 \%)$ & $17(34 \%)$ & \multirow{7}{*}{$P>0.05$} \\
\hline Cord around Neck & $9(18 \%)$ & $11(22 \%)$ & \\
\hline Primi Breech & $4(8 \%)$ & $6(12 \%)$ & \\
\hline CPD & $4(8 \%)$ & $6(12 \%)$ & \\
\hline NPOL & $6(12 \%)$ & $7(14 \%)$ & \\
\hline UPI & $3(6 \%)$ & $2(4 \%)$ & \\
\hline Oligohydraminos & $3(6 \%)$ & $1(2 \%)$ & \\
\hline Duration of surgery & $28.26 \pm 5.55$ & $27.36 \pm 5.76$ & 0.428 \\
\hline
\end{tabular}

Data presented as Mean \pm SD or number (percentage) as appropriate

CPD- Cephalo Pelvic Dispropotion, NPOL- Non Progress of Labour, UPI- Utero Placental Insufficiency

Table 2: Sensory and motor block characteristics

\begin{tabular}{|c|c|c|c|c|}
\hline \multicolumn{2}{|l|}{ Variables } & $\begin{array}{c}\text { Group L } \\
(\mathbf{n}=\mathbf{5 0})\end{array}$ & $\begin{array}{c}\text { Group B } \\
(\mathbf{n}=\mathbf{5 0})\end{array}$ & P value \\
\hline \multicolumn{2}{|l|}{ 1.Time to $\mathrm{T}_{6}(\mathrm{~min})$} & $4.28 \pm 1.04$ & $3.8 \pm 0.81$ & 0.011 \\
\hline \multicolumn{5}{|l|}{ 2. Peak Sensory Level (PSL) } \\
\hline \multirow{4}{*}{$\begin{array}{l}\text { Patient distribution according to } \\
\text { PSL, } \mathrm{n}(\%)\end{array}$} & $\mathrm{T}_{3}$ & $1(2 \%)$ & $4(8 \%)$ & \\
\hline & $\mathrm{T}_{4}$ & $18(36 \%)$ & $23(46 \%)$ & \\
\hline & $\mathrm{T}_{5}$ & $5(10 \%)$ & $5(10 \%)$ & \\
\hline & $\mathrm{T}_{6}$ & $26(52 \%)$ & $18(36 \%)$ & \\
\hline \multicolumn{2}{|l|}{ Median (Range) } & $\mathrm{T}_{66} \mathrm{~T}_{6-} \mathrm{T}_{3)}$ & $\mathrm{T}_{44} \mathrm{~T}_{6-} \mathrm{T}_{3)}$ & \\
\hline \multicolumn{2}{|l|}{ Mean \pm SD } & $\mathrm{T}_{5.12+0.97}$ & $\mathrm{~T}_{4.74 \pm 1.03}$ & 0.060 \\
\hline \multicolumn{2}{|l|}{ 3.Time to PSL(min) } & $4.68 \pm 0.81$ & $4.44 \pm 0.63$ & 0.095 \\
\hline \multicolumn{2}{|l|}{ 4.Maximum Bromage Score } & 3 & 3 & \\
\hline \multicolumn{2}{|l|}{ 5.Time to reach Bromage $3(\mathrm{~min})$} & $3.56 \pm 0.63$ & $3.04 \pm 0.69$ & 0.0002 \\
\hline \multicolumn{2}{|l|}{ 6.Duration of Analgesia (min) } & $140.3 \pm 12.26$ & $155.7 \pm 14.35$ & 0.0001 \\
\hline \multicolumn{2}{|l|}{ 7.Sensory Block duration (min) } & $186.0 \pm 21.26$ & $210.7 \pm 22.18$ & 0.0001 \\
\hline \multicolumn{2}{|l|}{ 8.Motor block duration (min) } & $223.9 \pm 23.11$ & $250.9 \pm 24.20$ & 0.0001 \\
\hline
\end{tabular}

Data are presented as mean $\pm \mathrm{SD}$, median (range), $\mathrm{n}(\%)$ as appropriate 


\section{Discussion}

There is sparse data showing comparable efficacy of hyperbaric bupivacaine with isobaric levobupivacaine in CS. In these previous studies both agents were compared in doses of $\leq 10 \mathrm{mg}$ with fentanyl $l^{3,9,10}$ or alone ${ }^{7}$ and both agents were found effective in producing desired anesthesia even though levobupivacaine showed a little delayed onset, extent and duration of block. This discrepancy in clinical efficacy could be because of potency difference between two agents and the dosage of the drug used. Potency ratio of levobupivacaine/bupivacaine in spinal anesthesia is reported to be 0.87 (95\% C.1 $0.77-0.98$ ) by Lacassei et $\mathrm{al}^{11}$ and 0.71 (95\% C.1. 0.51-0.98) by Camorica et al. ${ }^{12}$ The doses of levobupivacaine used in above studies, were less than its $\mathrm{ED}_{95}$ dose for CS. In dose finding studies; $\mathrm{ED}_{95}$ dose of plain levobupivacaine for CS in subarachnoid block $(\mathrm{SAB})$ is reported to be $12.56 \mathrm{mg}(95 \%$ C. $1=11.16-13.97 \mathrm{mg}$ ) by Parpaglioni et $\mathrm{al}^{13}$ and $13.6 \mathrm{mg}(95 \%$ C. $1=11.8-$ $8.1 \mathrm{mg}$ ) by Khaw et al. ${ }^{14}$

Present study used $12.5 \mathrm{mg}$ of isobaric levobupivacaine which approximates its $\mathrm{ED}_{95}$ dose for CS and compared it with the most commonly used regime of $10 \mathrm{mg}$ hyperbaric bupivacaine in SA and found that both agents produced effective spinal anesthesia as evidenced by all patients in both groups achieving Target sensory level of $\mathrm{T}_{6}$ and complete motor block (Bromage score 3), and nil requirement of anesthetic supplementation, signifying $100 \%$ complete success rate in both groups. Previous studies have also showed similar success rate of levobupivacaine in CS. ${ }^{3,7,9}$ In present study, sensory onset and motor onset were significantly longer in Group L as compared to Group B; however this difference was of less than 1 min and was clinically not significant. Mean PSL was comparable in two groups $\left(\mathrm{T}_{4.74 \pm 1.03}\right.$ in group $\mathrm{B}$ and

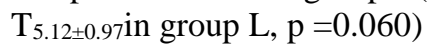

Previous studies which have compared isobaric levobupivacaine with hyperbaric bupivacaine in dose of $8.75 \mathrm{mg},{ }^{10} 10 \mathrm{mg},{ }^{3,7,9}$ reported that time to reach maximum sensory level and motor blockade were significantly longer in levobupivacaine group than in bupivacaine group. The difference was around 3-5 mins. This slower onset of sensory-motor block with isobaric levobupivacaine in these studies ${ }^{2,3,9}$ could be attributed to potency difference between two agents (levobupivacaine/ bupivacaine -0.71$)^{5}$ and the dose of isobaric levobupivacaine used in these studies were lesser than its $\mathrm{ED}_{95}$ dose for $\mathrm{CS}$ which was documented as $12.56 \mathrm{mg}$ (C.I 95\%: $11.16-13.97)^{13}$ and $13.6 \mathrm{mg}$ (C.I 95\%: $11.8-18.1 \mathrm{mg}){ }^{14}$

Inspired by above finding at the outset we hypothesized that by increasing the dose of isobaric levobupivacaine to $12.5 \mathrm{mg}$ (which approximates the $\mathrm{ED}_{95}$ dose), we would be able to shorten the onset time of sensory-motor block and it would produce clinically comparable block characteristics as of $10 \mathrm{mg}$ hyperbaric bupivacaine (most commonly used regime). This increase in dose of isobaric levobupivacaine would help to compensate the potency difference of the two agents and comparable motor and sensory blockades with two agents can be achieved. Our results proved this hypothesis.

Hemodynamic stability with isobaric levobupivacaine was comparable to that of hyperbaric bupivacaine but incidence of hypotension, nausea \& vomiting were relatively less in group $\mathrm{L}$ as compared to group B as observed by older studies. $3,7,9,15,16$ One more advantage of isobaric levobupivacaine is its property of reduced cardio and neurotoxicity. Evidence suggest that levobupivacaine has reduced potential of myocardial depression and arrhythmogenicity and provide greater margin of safety than racemic bupivacaine as proved in animal studies (Santos et al, 2001), ${ }^{17}$ as well as human volunteer studies (Bardsley et al, 1998). ${ }^{18}$ Intrathecal use of isobaric levobupivacaine in various studies $^{3,7,9,15,16}$ has demonstrated good tolerability and good clinical efficacy without any neurotoxic effects like cauda equina syndrome, transient neurological symptoms (TNS) and arachnoiditis.

Present study got a limitation in terms of not studying $10 \mathrm{mg}$ of isobaric levobupivacaine as one of the group which would have given a better picture for comparing the efficacy of ED 95 dose $(12.5 \mathrm{mg})$ and 10 $\mathrm{mg}$ of hyperbaric bupivacaine to reach a definite conclusion. The reasons being high failure rate and delayed effect with the use of $10 \mathrm{mg}$ of levobupivacaine in the pilot study in CS conducted initially.

\section{Conclusion}

Present study concludes that isobaric levobupivacaine $(12.5 \mathrm{mg})$ can be utilized a suitable alternative to hyperbaric bupivacaine $(10 \mathrm{mg})$ in spinal anesthesia for cesarean section. This drug is effective enough to produce the sensory motor blockade with clinically comparable onset time and stable hemodynamic profile. In addition, this novel drug levobupivacaine may offer the advantage of decreased cardiovascular and central nervous system toxicity.

\section{Conflict of Interest: None}

\section{References}

1. American Society of Anesthesiologists Task Force on Obstetric Anesthesia Practice guidelines for obstetric anesthesia: an updated report by the American Society of Anesthesiologists Task Force on Obstetric Anesthesia. Anesthesiol. 2007;106:843-863.

2. Tetzlaff JE, O'Hara J, Bell G, Grimm K, Yoon HJ. Influence of baricity on the outcome of spinal anesthesia with bupivacaine for lumbar spine surgery. Reg Anesth. 1995;20:533-537.

3. Dar FA, Mir IH, Bhat HA. Comparison of intrathecal hyperbaric bupivacaine and levobupivacaine for Cesarean section. Ain-Shams J Anesthesiol. 2015;08:89-92. 
4. Bremerich DH, Kuschel S, Fetsch N, Zwissler B, Byhahn $\mathrm{C}$, Meininger D. Levobupivacaine for parturients undergoing elective caesarean delivery. A dose-finding investigation. Anesthesist. 2007;56:772-779.

5. Gori F, Corradetti F, Cerotto V, Peduto VA. Influence of positioning on plain levobupivacaine spinal anesthesia in cesarean section. Anesthesiol Res Pract. 2010; 2010: Article ID 21269616.

6. Vicent O, Litz RJ, Hübler M and Koch T. Secondary cranial extension after spinal anesthesia with isobaric $0.5 \%$ bupivacaine following postural change. Anesthesist. 2003;52(11):1035-1038.

7. Duggal R, Kapoor R, Moyal G. A comparison of intrathecal levobupivacaine with hyperbaric bupivacaine for elective cesarean section: A prospective randomized double-blind study. J Obstet Anesth Crit Care. 2015;5(2):78-83.

8. Hopkins, W. G. (2000). A new view of statistics. Internet Society for Sport Science:

http://www.sportsci.org/resource/stats.

9. Guler G, Cakir G, Ulgey A, Ugur F, Bicer C, Gunes I, et al. A Comparison of spinal anesthesia with levobupivacaine and hyperbaric bupivacaine for cesarean sections: A randomized trial open. J Anesthesiol. 2012;2:84-89.

10. Prabha P, Shreyavathi R, Raghavendra Rao RS, Rao A. comparative study of intrathecal bupivacaine and levobupivacaine with fentanyl for caesarian section. Sch J App Med Sci. 2014;2(4B):1255-1259.

11. Lacassie HJ, Columb MO, Lacassie HP and Lantadilla RA. The relative motor blocking potencies of epidural bupivacaine and ropivacaine in labor. Anesth Analg. 2002;95(1):204-208.

12. Camorcia M, Capogna G, Berritta C, Columb MO. The relative potencies for motor block after intrathecal ropivacaine, levobupivacaine, and bupivacaine. Anesth Analg. 2007;104(4):904-907.

13. Parpaglioni R, Frigo MG, Lemma A, Sebastiani M, Barbati G and Celleno D. Minimum local anesthetic dose (MLAD) of intrathecal levobupivacaine and ropivacaine for Caesarean section. Anesth. 2006;61:110-115.

14. Khaw K, Ngan Kee WD, Ng F, Leung P. Dose-finding comparison of spinal levobupivacaine and bupivacaine for caesarean section. Int J Obstet Anestha. 2004;13:S17.

15. Goyal A, Shankaranarayan P, Ganapathi P. A randomized clinical study comparing spinal anesthesia with isobaric levobupivacaine with fentanyl and hyperbaric bupivacaine with fentanyl in elective cesarean sections. Anesth Essays Res. 2015;9:57-62.

16. Deori A K, Das A, Borgohain D, Bora D, Saikia A, Tiwari P K. A comparative study of spinal anesthesia with levobupivacaine and hyperbaric bupivacaine for cesarean sections. Int J Contemp Med Res. 2016;3 (7):1902-1905.

17. Santos AC, DeArmas PI. Systemic toxicity of levobupivacaine, bupivacaine and ropivacaine during continuous intravenous infusion to nonpregnant and pregnant ewes. Anesthesiol. 2001;95:1256-1264.

18. Bardsley H, Gristwood R and Baker H. A comparison of the cardiovascular effects of levobupivacaine and racbupivacaine following intravenous administration to healthy volunteers. Br J Clin Pharmacol. 1998;46:245249.

How to cite this article: Madhanmohan $C$, Naithani U, Gupta M, Verma V, Damor P. Comparison of isobaric levobupivacaine versus hyperbaric bupivacaine in spinal anesthesia for cesarean section: A prospective randomized case control study. Indian J Clin Anaesth. 2018;5(4):549-555. 